\title{
Covid-19 Variants in Morocco
}

\author{
Rachid Ait Addi ${ }^{1}{ }^{*}$, Abdelhafid Benksim ${ }^{1,2}$ and Mohamed Cherkaoui ${ }^{1}$ \\ ${ }^{1}$ Laboratory of Human Ecology, Department of Biology, School of Sciences Semlalia, Cadi Ayyad University, Morocco \\ ${ }^{2}$ High Institute of Nursing and Technical Health, Morocco
}

*Corresponding author: Rachid Ait Addi, Laboratory of Human Ecology, Department of Biology, School of Sciences Semlalia, Cadi

Ayyad University, Marrakech, Morocco

\begin{tabular}{|c|c|}
\hline ARTICLE INFO & ABSTRACT \\
\hline Received: 豐 May 14, 2021 & $\begin{array}{l}\text { Coronavirus disease } 2019 \text { is a respiratory sickness that may spread be-tween } \\
\text { persons. It is caused by a novel coronavirus that produces an outbreak in Wuhan, China }\end{array}$ \\
\hline Published: 蔧 May 24, 2021 & $\begin{array}{l}\text { and spread all over the world to become a pandemic. From the appearance of the first } \\
\text { case of the new coronavirus in Morocco, Moroccan authorities has spared no effort to }\end{array}$ \\
\hline $\begin{array}{l}\text { Citation: Rachid Ait Addi, Abdelhafid } \\
\text { Benksim, Mohamed Cherkaoui. Covid-19 } \\
\text { Jariants in Morocco. Biomed J Sci \& Tech } \\
\text { Res 36(1)-2021. BJSTR. MS.ID.005788. } \\
\text { Keywords: Covid-19; Morocco; Vaccina- } \\
\text { ion; Pandemic; Covid-19 variants }\end{array}$ & $\begin{array}{l}\text { promote the health of Moroccans, ahead ofthat of the country's economy. On } 28 \text { th January, } \\
\text { the campaign started, and the King of Morocco was the 1st Moroccan to be vaccinated } \\
\text { against the coronavirus. Thereafter, on } 27 \text { April 2021, the people fully vaccinated in } \\
\text { Morocco is } 11,47 \% \text {. In December 2020, a new variant of SARS-CoV-2 emerged in the UK } \\
\text { (United Kingdom) before entering Morocco. With a transmissibility of } 30 \text { to } 70 \% \text { higher } \\
\text { than the strains of SARS-CoV-2 previously circulating in the world, UK variant is present } \\
\text { in seven regions of Morocco. Other variants emerged in Brazil, South Africa, and recently } \\
\text { in India. Thus far, only two cases of Indian variant have been detected in Morocco. This } \\
\text { study demonstrates that Morocco is controlling the propagation of Covid-19 pandemic } \\
\text { and specially Covid-19 variants by anticipating lockdown and partial containment. }\end{array}$ \\
\hline
\end{tabular}

\section{Introduction}

Coronavirus disease 2019 (Covid-19) is a respiratory sickness that may spread be-tween persons. It is caused by a novel coronavirus that produced an outbreak in Wuhan, China, and spreads all over the world to become a pandemic [1-3]. The symptoms associated with COVID-19 are fever, cough, and fatigue, congestion, rhinorrhea, olfactory dysfunction, sore throat and diarrhea [4,5]. COVID-19 is primarily transmitted through respiratory droplets, which are released when a person sneezes, coughs, or talks. Furthermore, when a person touches a contaminated surface or object, and then touches his mouth, nose, or eyes may get infected [6-8]. As of Mai 02, 2021, Covid-19 has affected more than 511,856 people in Morocco, of which 9,028 have died, while 498,415 have recovered [9].

Furthermore, from the appearance of the first case of the new coronavirus in Morocco, His Majesty King Mohamed VI launched a special COVID-19 fund (more than 3,8 billion US dollar (USD) in contributions), initiated the National monitoring and response plan against Coronavirus infection and the vaccination campaign against COVID-19 [10]. with its experience of containing pandemics especially H1N1 pandemic in 2009, the Moroccan government launched the National monitoring and response plan Coronavirus infection whose objectives are

1) Prevent the introduction into the national territory of SARS-Cov 2.

2) Detect cases early and contain their spread.

3) (Organize a national response adapted from the health system; and

4) Strengthen infection prevention and control measures in hospitals [11].

The limitation of people circulating outside their home, social distancing, the cessation of almost all working activities and the request to the population to use protective masks and gloves all have the aim of minimizing the likelihood that people who are not infected come into contact with others who are already infected and probably still asymptomatic [12]. In Addition, Moroccan 
government decided to sus-pend travel to the countries most affected by the pandemic, and soon after to close the borders. On 28 January, the campaign started, and the King of Morocco was the 1st Moroccan to be vaccinated against the coronavirus [11]. On 27 April 2021, the people fully vaccinated in Morocco is 11,47 \% [13].

In December 2020, a new variant of SARS-CoV-2 emerged in the UK before entering Morocco. Known as lineage 20B / 501Y. V1, VOC 202012/01 or B.1.1.7), this variant, now detected in 130 countries, is starting to spread like wildfire in the kingdom. With a transmissibility of 30 to $70 \%$ higher than the strains of SARS$\mathrm{CoV}-2$ previously circulating in the world, the mutating virus is present in seven regions of Morocco. This is what the SARS-CoV2 (Covid-19) genomic watch device reveals. Indeed, the sequencing of the complete genome allowed the confirmation of the presence of signature mutations of the British variant 89 strains B.1.1 .7 (British variant) have been assigned, and no other variant of concern (VOC) has been confirmed in Morocco" [14-16].

The South African variant emerged around the same time as the English one and has since been detected in at least 20 countries. Genomic data from South Africa suggested that the variant, known as 501Y.V2, quickly displaced other circulating lineages in the country as it appears to have a higher viral load and is therefore more transmissible.4 These variant shares similarities with the English and Brazilian variants in that it contains both the N501Y and E484K spike protein mutations [17].

Another variant, known as P.1 or V0C202101/02 in the UK, was first detected in travel-lers from Brazil who arrived in Japan in January 2021. It involves 17 unique amino acid changes, three deletions, four synonymous mutations, and one 4 nt insertion. It has several mutations that are known to be biologically important, including E484K and N501Y.The N501Y mutation, which is also a feature of the English variant, has been linked to increased infectivity and virulence in mouse models. Meanwhile, the E484K mutation is thought to be associated with escape from the neutralizing antibodies produced by the body against SARS-CoV-2. This mutation is pre-sent in the South African variant as well has not yet been detected in Morocco, and travel bans have been put in place to try to prevent it reaching the country [17]. The mutations found in the Indian variant are identified as E484Q and E484K.They are known in other mutations as well they are not entirely new. They have been detected in the South African variant, B.1.353, and in the Brazilian variant. In some cases, the Indian mutations were detected in the British variant, B.1.1.7. There are other mutations, such as one called L452R, which is detected in a Californian variant of the virus, B.1.429. The same was found in a variant in Germany.

In the Indian state of Maharashtra, over $60 \%$ of all coronavirus infections have been linked to the new B.1.617 variant, based on the infections that have been sequenced for their origin $[18,19]$. The new variant, which has a so-called double mutation, is thought to be fueling India's deadlier new wave of cases that has made it the world's second worst-hit country, surpassing Brazil again, and has already begun to overwhelm its hospitals and crematoriums. India has reported more than 14.5 million Covid cases so far and more than 175,600 fatalities [20]. In fact, India is experiencing an unprecedented rise in the number of coronavirus infections. This Asian country has recorded more than 300,000 cases per day since April 22, which has resulted in saturation of the country's health system and a serious shortage of hospital beds, oxygen and drugs [21].

Morocco announced on Monday the detection of two confirmed cases of the Indian strain of the coronavirus in Casablanca (the country's largest city). These are the first two cases of the Indian variant detected in this Arab country [21]. Moroccan health authorities first spoke with the two people who were positive for the Indian variant in order to identify possible contact cases. The aim was to list all the people who had been in contact with the two cases over a period ranging from 2 days before the onset of the first symptoms until the $14^{\text {th }}$ day of the disease. All the people identified through this process were contacted by the authorities to inform them, then to set up the planned monitoring system, which will extend until the end of the second week after having been in contact with the contaminated case.

Actually, Morocco had put in place an anticipatory strategy to manage the Indian variant crisis. Since April 24,2021, and while no case had yet been detected in the kingdom, all flights from or to India have been suspended to prevent this new variant, deemed to be more contagious, from spreading. in Morocco. To our knowledge, our study in COVID-19 variant is the first one in Morocco and Africa. It demonstrates that Morocco is controlling the propagation of Covid-19 pandemic and specially Covid-19 variants by anticipating lockdown and partial containment.

\section{Author Contributions}

Conceptualization, R.A.; methodology, R.A.; validation, R.A.,formal analysis, R.A.; investigation, R.A.; writing, R.A; original draft preparation, R.A.; writing-review and editing, R.A.; visualization, R.A, A.B.; supervision, M.C.; All authors have read and agreed to the published version of the manuscript.

\section{Funding}

This research received no external funding.

\section{Acknowledgments}

We would like to express our gratitude to His Majesty King Mohammed VI for all his leading initiatives in COVID-19 management and putting all the necessary means to fight the pandemic. We also thank the health workers for their hard work against the pandemic, all the peer reviewers and editors for their opinions and suggestions. Finally, authors declare no funding support. 


\section{Conflicts of Interest}

The authors have no conflict of interest to disclose.

\section{References}

1. (2019) World Health Organization (2019) Report of the WHO-China Joint Mission on Coronavirus Disease 2019 (COVID-19).

2. Li R, Pei S, Chen B, Song Y, Zhang T, et al. (2020) Substantial undocumented infection facilitates the rapid dissemination of novel coronavirus (SARSCoV2). Science.

3. Ait Addi R, Benksim A, Amine M, Cherkaoui M (2020) COVID-19 Outbreak and Perspective in Morocco. Electron J Gen Med 17(4): em204.

4. Guan WJ, Ni ZY, Hu Y, Liang WH, Ou CQ et al. (2020) Clinical characteristics of coronavirus disease 2019 in China. N Engl J Med 382(18): 1708-1720.

5. Lechien JR, Chiesa-Estomba CM, Place S, Van Laethem Y, Cabaraux P, et al. (2020) Clinical and epidemiological characteristics of 1420 European patients with mild-to-moderate coronavirus disease 2019. J Intern Med 288(3): 335-344

6. Ait Addi R, Benksim A, Cherkaoui M (2020) Oral covid-19 disclosing test: A novel rapid technique in infection diagnosis. Open Public Health Journal 13(1).

7. Mehmet Akif YAZAR, Yasin TIRE, Fatih YUCEL, Hasan SENAY, Ercan KURTIPEK, et al. (2021) Clinical characteristics of critically Ill patients with 2019 novel coronavirus (COVID-19): do we need a new triage system? Signa Vitae.

8. Ait Addi R, Benksim A, Cherkaoui M (2020) Vulnerability of People with Cancer and the Potential Risks of COVID-19 Pandemic: A perspective in Morocco. Signa Vitae 16(1):207-208.

9. Our world in data. Coronavirus Pandemic (COVID-19)-the data.

10. (2021) Vaccins anti-Covid-19: le Maroc prend le taureau par les cornes

ISSN: 2574-1241

DOI: $10.26717 /$ BJSTR.2021.36.005788

Rachid Ait Addi. Biomed J Sci \& Tech Res

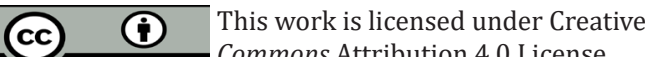

Submission Link: https://biomedres.us/submit-manuscript.php
11. Premkumar M, Sundararajan T (2020) DLDM: Deep Learning-Based Defense Mechanism for Denial-of-Service Attacks in Wireless Sensor Networks. Microprocessors and Microsystems: 103278.

12. Zhang Y, Zeng G, Pan H, Li C, Hu Y, et al. (2021) Safety, tolerability, and immunogenicity of an inactivated SARS-CoV-2 vaccine in healthy adults aged 18-59 years: A randomised, double-blind, placebo-controlled, phase 1/2 clinical trial. Lancet Infect Dis 21(2): 181-192.

13. Ait Addi R, Benksim A, Cherkaoui M (2021) The vaccination against COVID-19 in Morocco: a success story in progress. Signa Vitae 17(3): 250-255.

14. H 1413 Covid-19: le variant britannique mute au Maroc.

15. Mahase E (2020) Covid-19: What have we learnt about the new variant in the UK? BMJ: 371: m4944.

16. The value of information. Morocco: Covid-19 UK Variant Detected in 7 Regions -Official.

17. Mahase E (2021) Covid-19: What new variants are emerging and how are they being investigat-ed? BMJ 372: n158.

18. Palacios R, Patino EG, De Oliveira Piorelli R, Conde MTRP, Batista AP, et al. (2020) Double-blind, randomized, place-bo-controlled phase III clinical trial to evaluate the efficacy and safety of treating healthcare professionals with the adsorbed COVID-19 (inactivated) vaccine manufactured by Sinovac - PROFISCOV: A structured summary of a study protocol for a randomised controlled trial. Trials 21(1): 853.

19. Folegatti PM, Ewer KJ, Aley PK, Angus B, Becker S, et al. (2020) Safety and immunogenicity of the ChAdOx1 $\mathrm{nCoV}-19$ vaccine against SARSCoV-2: A preliminary report of a phase $1 / 2$, single-blind, randomised controlled trial. Lancet 396(10249): 467-478.

20. (2021) Is a double mutant COVID variant behind India's record surge?

21. Covid-19: Deux cas du variant indien confirmés au Maroc. Covid-19: Deux cas du variant indien confirmés au Maroc (aa.com.tr).

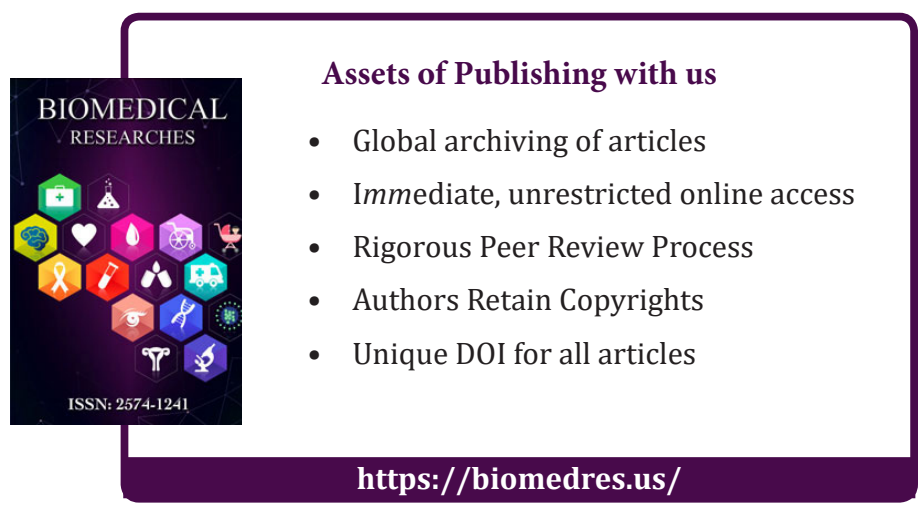

